\title{
WHEAT DIET AND LEPROSY
}

$\mathrm{I}^{\mathrm{N}}$ a valuable paper published recently, Drs. R. G. Cochrane and M. Paulraj, and Miss M. D. Salmond (Indian J. Med. Res., 27, 4; 1940) discuss the results of their treatment of certain symptoms in leprosy by the administration of a wheat diet. The experiments were carried out at the Lady Willingdon Leper Settlement during the last two years.

The authors point out that it has been recognized since the publication of Jonathan Hutchinson's book on leprosy and fish-eating in the latter part of the nineteenth century that there is a strong possibility that the causative factors of the disease may be dietary. However, most workers are of the opinion that the spread of leprosy in individual communities is attributable more to contact with open cases than to nutritional deficiencies. The authors have been working on the problem from the dietary aspect but as yet their findings are in general still inconclusive, and therefore they confine their report to a single observation regarding the value of a wheat diet in the relief of painful neuritis and certain joint pains. The experiments were carried out to test the suggestion that excessive consumption of carbohydrates may be responsible for metabolic imbalance. Wheat was therefore substituted for rice in the diet of the patients.

Thirty-seven cases were examined, and in every case where the wheat diet was consumed for three months or more, there was either complete relief or substantial alleviation of the painful symptoms. One curious difficulty experienced during the course of the work was the great reluctance of the Indian patients to take wheat instead of rice. In some cases, even when relief had been obtained from the wheat diet, the patients insisted on returning to rice. For adults 21 ounces, and for children 12 ounces, were the amounts of wheat administered each day. Throughout the investigation, the patients continued to receive the standard treatment of the institution for leprosy.

Analysis of the results shows that of patients treated for bone pain, $85 \cdot 7$ per cent showed complete relief, and 14.3 per cent partial relief. The corresponding figures for nerve pain were 69.5 and 30.5 per cent. The authors point out that whereas there was a constant improvement in nerve pain, there was no corresponding improvement in the leprosy condition. In reply to the possible objection that there were no controls, they state that as none of the patients had responded to palliative treatment beforehand, they automatically constituted controls themselves.

In conclusion, the authors state that their experiments show that the new method is worthy of trial where previous remedies have failed. It should be tried as a therapeutic measure before resorting to operative methods for painful neuritis, except in cases where there is a marked swelling of the nervesheath and threatened abscess-formation. The method, in addition to the hydnocarpus treatment, does not appear to hasten the disappearance of Mycobacterium leprae from the skin and mucous membrane of the nose.

\section{SCIENTIFIC AND INDUSTRIAL RESEARCH IN NEW ZEALAND}

$\mathrm{T}$ HE fourteenth annual report of the Department of Scientific and Industrial Research, New Zealand*, includes the Minister's statement together with the report of the secretary, and the reports of the several research committees of the Council as well as reports on research work at the agricultural colleges,- the Physical Testing Laboratory, the Dominion Laboratory, the Geological Survey Branch, the Dominion Observatory, the Magnetic Observatory and Meteorological Branch. Immediately on the outbreak of war, the resources of the Department were placed at the disposal of the defence authorities, the Ministry of Supply, and the various controllers operating thereunder.

Investigations relating to problems of supply, increase of production and conservation of natural resources were initiated by the Department itself. The campaign against plant diseases and insect pests has been intensified and in view of the importance of soil survey to land development, those in progress are being accelerated as much as possible and a survey of the soil of the North Island is already well advanced.

A new industry which is now well on the way to

* New Zealand. Fourteenth Annual Report of the Department of Scientifle and Industrial Research. Pp. 100. (Wellington: Government Printer, 1940.) 28 . successful establishment is the production of linen fibre. Prior to the outbreak of war, investigations, both local and overseas, into the possibilities of establishing such an industry had been made with very encouraging results. Trial planting of selective varieties of linen flaxes in Canterbury showed that fibre of the desired quality could be successfully grown and would at the same time provide for a profitable diversification of farming practice. Further developments in the war cut off the supplies of linen fibre formerly obtained by Britain from European sources, and an appeal was made to the Dominions to accelerate production of linen flax as rapidly as possible to help to meet the deficiency.

The Department is giving special attention to methods of storing fruit and dairy produce designed to meet emergency conditions. The research carried out on the cold storage of fruit has covered refrigerated gas storage of apples, the effect of fertilizers on storage quality, and wastage in citrus fruits. A programme of orchard storage experiments designed to give information to enable the best methods of nonrefrigerative storage to be adopted, is also planned, as well as the erection of a semi-commercial scale refrigerated gas store. Close liaison has been established with the Department of Industries and Com- 